\title{
DEVELOPING A WORKSTATION FOR STOCKTRADERS
}

\author{
I V Burmistrov
}

Russian Trading System Technical Centre and Moscow State University, Russia

\section{INTRODUCTION}

Since Russia's privatizations in 1992, activities have focused on developing an infrastructure to trade, clear and register corporate securities. The Russian Trading System (RTS), launched in July 1995, is Russia's largest fully electronic system for over-the-counter (OTC) securities trading. Today, the RTS consists of over 1000 workstations throughout the nation and abroad, connected to servers which link to a central processing complex in Moscow.

The RTS Technical Centre (RTS TC) was founded in October 1995 as a technical support centre to operate the RTS. Its main objective is to provide financial markets operators with technological tools to perform trading, manage front office and back office activities, organize the transmission of the data between the trading system, broker-dealer firms, clearing and settlement institutions, control authorities and to the public.

RTS TC is a service-oriented company. Our customers do not "buy" a product useful to solve a problem, they rather "entrust" the company to the solution of the problem, complete with the responsibility of updating the solution according to the stock market regulations modification and new developments in the stock market infrastructure.

From the very beginning, the building of the on-line trading system became the focal point of RTS TC activities. Initially, RTS traders used Portal ${ }^{\mathrm{TM}}$ software developed by NASDAQ. That was an obsolete character-based system with heavy keyboard operation. In September 1996, RTS started "from scratch" redevelopment of the stocktrader workstation for Microsoft Windows ${ }^{\mathrm{TM}}$ environment. The RTS TC formed a multidisciplinary redesign team whose skills included project management, software engineering, human factors and usability engineering. In August 1998, after two years of analysis, prototyping, usability evaluation, software engineering and coding, the new RTS Plaza workstation was launched.

In the following sections, we describe the effort of usability engineering team within the project and discuss lessons learned from development of user interface for such a specific workplace as that of stocktrader.

\section{PROCESS}

\section{Analysis of user activity for the stocktraders' population}

The usability team began with field studies of stocktraders' tasks and organizational structure of their work. To elicit users' task structure and formulate system requirements, dozens user interviews were conducted using an ethnographic interview approach (1). Each interview was accompanied by detailed observations on the actual dealing rooms. Using the data from the videotaped interviews and observation, a comprehensive task analysis was executed. Following execution of the task analysis for the existing tasks, additional new functions were identified and factored into the existing task structure to form a complete set of system requirements.

Main difficulties in our work were that (a) many of our users were persons with very high social status - in many cases, it was impossible to conduct conventional requirements gathering and usability testing procedures, and (b) very high level of secrecy in users' work many of them treated usability team members as a kind of information insiders appeared in their firms.

We overcame these difficulties mainly through painstaking analysis of massive recordings of traders' negotiations via chat facility. Supplementary method of information gathering was administration of questionnaires conducted via the Internet.

After formulating general principles of the new system, we developed paper prototypes of the new user interface and collected feedback from its prospective users. Then, programming team developed first runnable prototype of the system that has been installed in about twenty broker-dealer firms. The feedback from beta-testers has been collected and used for refinement of the user interface.

\section{Stocktraders activities in the OTC trading}

The OTC market has no trading centers. Instead, it consists of hundreds of brokerage firms located throughout the country and doing business by computer network and telephone. Firms in the OTC market are generally referred to as "broker-dealers", because they can sell and buy securities either as brokers (agents) or 
as dealers (principals). The OTC trading is being performed by traders in dealing rooms of broker-dealer companies (2).

Stocktraders have a continuous responsibility to buy shares at their published bid price or to sell shares at their offered price, whether or not they actually hold the shares. In this way broker-dealers make a profit on the difference between the prices at which they buy and those at which they sell. Primarily, dealing in shares takes place over the telephone between different brokerdealer firms' dealing rooms or by making transactions via the networked computer workstations. After a deal is made, whether through the telephone or computer workstation, it has to be recorded and transferred to the trading system's centralized database as well as traders have to write a record of the deal on the paper ticket. The ticket is then picked by back-office staff (3).

Stocktraders have a range of devices to assist them in understanding the current state of the market and making trading decisions: advanced telephony, displays for monitoring prices at different markets, signals from analytic software packages, terminals of news agencies, such as Bloomberg and Reuters, local and international TV news, Internet terminals with different financial and political information, Internet based chat and conferencing facilities for financial professionals. Traders are often bounce back and forth among the various monitors.

\section{Collaboration in a dealing room}

Individual stocktraders in the dealing room are sensitive to, and monitor, activities within the local milieu, whilst participating in relatively distinct activities and tasks. Traders, however, are not simply remaining sensitive to the local environment of action and to discriminate what may be relevant to their tasks. Rather, work within the dealing room demands that whilst they are engaged in one activity they may have to participate simultaneously in the activities of colleagues. For example, traders who are apparently engaged in the telephone, may make recommendations to a colleague as to what he should buy or sell, or may publicize the purchase within all his colleagues in the dealing room (3). When designing a trading workstation, it is important to provide support for such collaborative activities within the computer system.

\section{Selection of appropriate user interface guidelines}

Of all the white-collar professions, modern stock trading is one of the most complex and stressful. Traders must perceive and analyze huge amounts of news and market information fed simultaneously from different news agencies and different trading floors. They must extensively communicate to other traders in their own companies and counterparty firms. Based on these activities, they must make immediate decisions, on their own risk and responsibility.

The analysis of user activities showed that, in many aspects, they are similar to those of the plant operators in control rooms in continuous process industries, air traffic controllers, or high-ranked officers in command and control military settings. RTS Plaza design is based on electronic warfare techniques. In the trading war (4), the enemy is primarily counterparty - other brokerdealer firm. This understanding guided the development of the trader's workstation and the choice of user interface standards and guidelines. In fact, the RTS Plaza user interface is the "user interface for the battlefield".

We developed our own set of user interface guidelines different from conventional guidelines for windowing applications in "office" work environments. In particular, many elements usual for desktop-oriented environments such as overlapping windows and pop-up dialogues were banned in our guidelines, because they are extremely navigationally loaded and may hide important information. Instead, fixed screen arrangement of information and control areas was recommended. The main reason behind this decision is that speed of interaction with the system is a crucial factor in trading. Fixed arrangement of screen areas supports sensorimotor coordination, speeds up visual search, and minimize a waste of time during window navigation activities, such as window selection, pressing the buttons or scrolling.

\section{PRODUCT}

In the military environment, the systems are designed to receive, filter, and generate information based on massive volumes of different inputs, and to provide decision support for crucial actions. RTS Plaza realizes similar functionality - filters stocks, receives price inputs and reports trades, alerts trader to market movements, i.e. buy and sell opportunities, maintains peer-topeer communication between counterparties, and broadcasts financial and political news coming from the information agencies.

\section{Screen arrangement and basic functionality}

Although it is based on conventional Microsoft Windows ${ }^{\mathrm{TM}}$ screen elements and controls, and is fully integrated into Microsoft Windows ${ }^{\mathrm{TM}}$ operating systems, the RTS Plaza user interface is quite different from usual office-style interfaces. The RTS Plaza interface is not "windowing", but "frame-based", or "tiling" interface (see Figure 1).

In contrast to windowing interface, the tiling interface is the display environment in which users do not lose their view of the process or alarm status, even while they access and view data in multiple screen areas from a number of sources. They have complete control over 


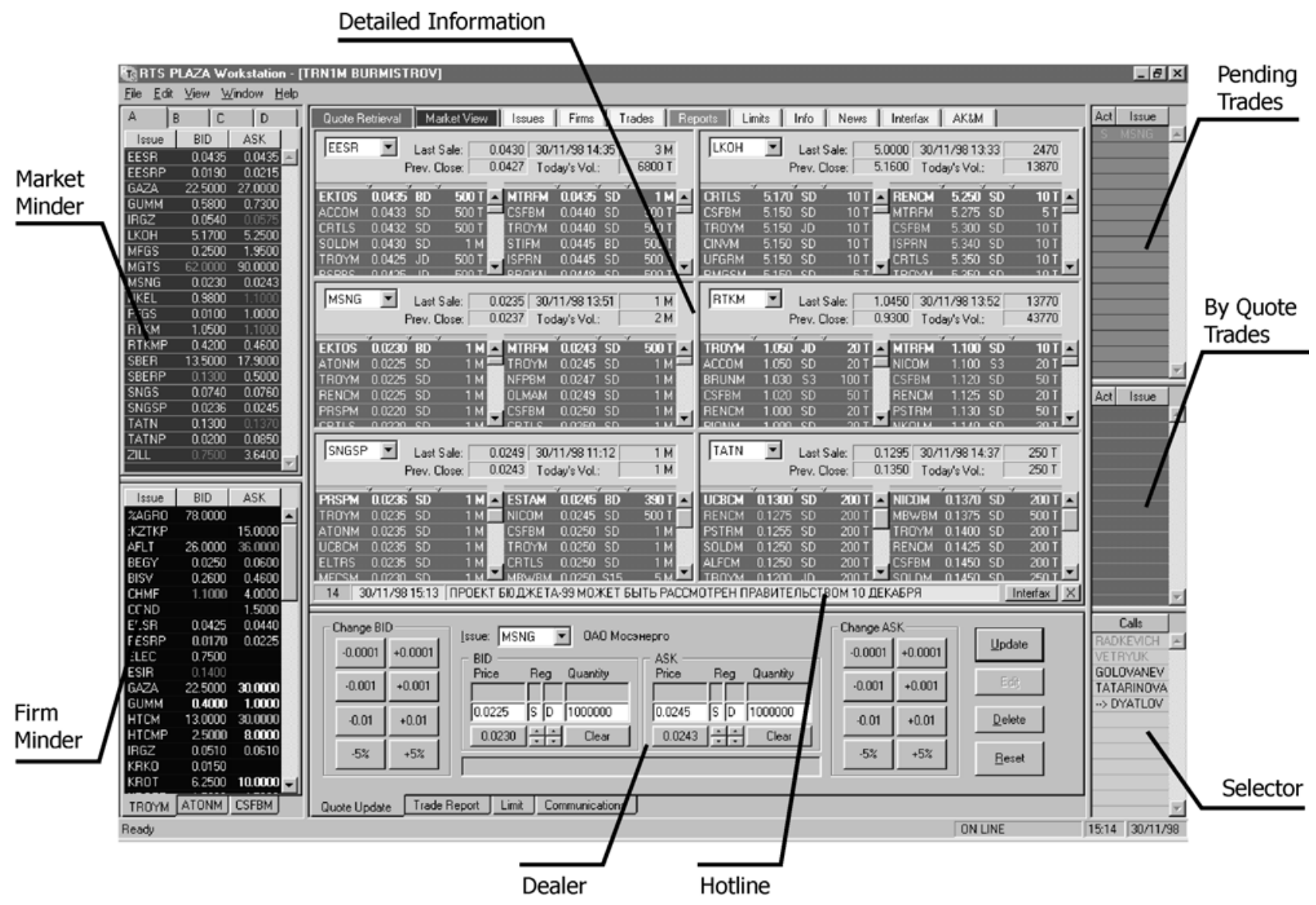

Figure 1: RTS Plaza user interface

every tile in their system, and interact with permanent windows that can never be hidden or overlaid.

RTS Plaza screen consists of eight tiles, which can contain several cells or tabs.

Market Minder. This is a list of best bids and asks for groups of stocks of interest to the trader. Prices are color coded from previous to indicate market movements. Market Minder provides global view of market tendencies, while more detailed information on particular stocks is available in Quote Retrieval and Trades tabs.

Firm Minder. This tile contains full lists of quotes for individual broker-dealer firms of interest to the trader. Prices are color coded from previous to indicate individual counterparty's market strategy. This allows trader to anticipate consequences of enemy's current actions.

Detailed Information. Consists of nine tabs with detailed information on particular stocks (Quote Retrieval), directories of stocks and companies (Issues and Firms), ticker of all trades executed within the trading system (Trades), record of trades executed by the company (Reports), and three news feeds from different information agencies (RTS News, Interfax and AK\&M).

Hotline. This is a one-string area to present alerts to important market events and to show news headlines as they happen. Trader then can press a button to get the full story in RTS News, Interfax and AK\&M tabs.

Dealer. This tile consists of three tabs for entering quotes (Quote Update), reporting trades (Trade Report), and maintaining text communications between traders (Communications).

Pending Trades and By Quote Trades. These are lists of trades waiting confirmation by trader or its counterparty, and information about automatic trades that do not need confirmation.

Selector. This is a switchboard for communications between traders.

\section{Interaction style}

Since speed is a key issue in trading, especially in very high workload situations (breakouts), it is important to choose appropriate main interaction style. The primary interaction style in RTS Plaza is drag-and-drop operation via the mouse. About $90 \%$ of data input and manipulation can be performed with single input device, 
a mouse, therefore, with one hand, thus releasing second hand for other activities, e.g. holding a telephone handset.

For example, dragging-and-dropping a stock of interest from the Market Minder to one of the Quote Retrieval's cells replaces that cell with detailed representation of the chosen stock; dragging-and-dropping a quote from the Quote Retrieval cell to the Trade Report tab initiates trade reporting action; dragging-and-dropping "an incoming call" from the Selector list to the Communications tab works as "picking up the phone handset".

\section{Screen space utilization}

The contradiction between the necessity to represent massive market information and limited screen "real estate" is common to any trading software. In the trading environment, trader is surrounded with a lot of displays that feed information from different trading systems, TV news, Internet, etc. From the very beginning, development of RTS Plaza workstation has been limited to a single screen.

Our approach to the problem was to represent highlevel information about the current state of the market alongside with more detailed information on particular stocks and activities of broker-dealer firms available on request.

RTS Plaza interface provides optimal proportion between representation of huge information feed and limited screen space. The user interface provides global view of the market via never-overlapped Market Minder tile, allowing more detailed analysis through Quote Retrieval and Trades tabs.

\section{Communication}

The system provides text-based peer-to-peer chat facility via Communications tab. This facility is an important low-pace communicative supplement to extensive conventional phone communication, which allows traders to maintain long-term contacts with multiple counterparties during all the trading session.

\section{Support of collaboration}

RTS Plaza supports a number of collaborative activities such as silent communication between traders via the Communications tab and publicizing quotes and deals within the dealing room via Firm Quotes and Pending Trades tiles. This greatly reduces the "shouting across the floor" aspect of the dealing room and the amount of interruptions in individual traders' activities.

\section{Alerts}

RTS Plaza is designed to filter vast amounts of stock data from about 450 stocks and to provide alerts to traders relating to the movements and trends in the stock market. The system color-codes every inside bid/ask change for each stock selected by the trader to be tracked in Market Minder tile.

Besides color coding, special never-overlapped screen areas, Hotline and Pending Trades are used to alert trader about important news and events on the market and necessity to perform urgent actions, e.g. to confirm counterparty's trade report. The tiling interface and color-coding make alerts more persistent and prominent.

\section{Software upgrade and maintenance}

RTS Plaza workstations were installed in more than 500 companies all over Russia as well as abroad. The issue of efficient software upgrade and maintenance is a cornerstone of the system success. All software modules are upgraded remotely and transparently to the user. The new version is replicated to the user workstation during the work session and once the replication completed, the modules are changed at the beginning of a new work session or immediately, as set up by the system administrator. This solution allowed us to reduce the number of field engineers and considerably reduce a period between the introduction of new versions of the software.

\section{ACKNOWLEDGEMENT}

The author would like to thank Chauncey Wilson, WilDesign Consulting, for her stimulating comments.

\section{REFERENCES}

1. Wood, L. E., 1997, "Semi-structured interviewing for user-centered design", interactions, 4(2), 48-61

2. Dalton, J. M. (Ed.), 1993, "How the stock market works" (2nd ed.), New York Institute of Finance, New York, USA

3. Heath, C., Jirotka, M., Luff, P., and Hindmarsh, J., 1995, "Unpacking collaboration: the interactional organisation of trading in a City dealing room", CSCW, $\underline{3}, 147-165$

4. McCall, R. D., 1997, "The Way of the WarriorTrader", McGraw-Hill 